\title{
High Current Electron-probe Microanalysis of Ni and Co in Olivine in the NWA 773 Lunar Meteorite Clan
}

\author{
K.E. Gibson*, B.L. Jolliff*, and P.K. Carpenter*
}

*Department of Earth and Planetary Sciences and the McDonnell Center for the Space Sciences, Washington University in St. Louis, 1 Brookings Drive, St. Louis, MO 63130-4899

The NWA 773 clan is a group of lunar meteorites that contain three prominent lithologies of lunar volcanic and related intrusive rocks: olivine gabbro cumulate (OGC), olivine phyric basalt (OPB), and impact breccia. The NWA 773 clan has a unique geochemical signature among lunar mare basaltic meteorites $-\mathrm{a}$ low $\mathrm{TiO}_{2}$ content $\left(0.2-0.3 \mathrm{wt} \% \mathrm{TiO}_{2}\right.$ in the cumulate lithology) coupled with low $\mathrm{Eu} / \mathrm{Sm}$ and $\mathrm{Na} / \mathrm{Sm}[1]$. High-precision electron microprobe analyses of nickel and cobalt were made in olivine in the basalt and in cumulus olivine in clasts of olivine-gabbro cumulate in order to determine the distribution of trace elements and to understand the crystallization history of olivine in these rocks, and to determine relationships between the OGC and OPB.

Using Probe for EPMA ${ }^{\mathrm{TM}}$ software, we customized a routine to measure trace $\mathrm{Ni}$ and Co in olivine. Nickel and Co concentrations were measured simultaneously using LiF and LiFH (high intensity) wavelength-dispersive spectrometers (WDS) with summed intensities using the Probe for EPMA aggregate-intensity method on the JEOL JXA-8200 electron microprobe at Washington University. We used a $150 \mathrm{nA}$ probe current for $80 \mathrm{sec}$. (Ni) and $240 \mathrm{sec}$. (Co). Primary standards were synthetic Ni-olivine and Taylor Co metal. Secondary standards included synthetic fayalite, Corning 95IRW and 95IRX glass [2], and natural standards San Carlos and Boyd olivine. Corrections for peak overlap of $\mathrm{Fe} \mathrm{K} \beta$ on $\mathrm{Co} \mathrm{K} \alpha$ and $\mathrm{Co} \mathrm{K} \beta$ on $\mathrm{Ni} \mathrm{K} \alpha$ were included. $\mathrm{Ni}$ and Co point traverses were made with a beam diameter of $3 \mu \mathrm{m}$ and a step size of $5 \mu \mathrm{m}$. Coupled uncertainties and detection limits at a 99\% confidence level were 17 and $70 \mu \mathrm{g} / \mathrm{g}$ for $\mathrm{Ni}$ and 9 and $40 \mu \mathrm{g} / \mathrm{g}$ for Co, respectively. Projected detection limits (example in Fig 3) were modeled using the standard intensities and ZAF factors in order to project detection limits for given count times.

Olivine phenocrysts in OPB has the highest concentration of $\mathrm{Ni}$ in the Mg-rich phenocryst cores $(\sim 400-500 \mu \mathrm{g} / \mathrm{g})$, decreasing toward rims $(\sim 200-300 \mu \mathrm{g} / \mathrm{g})$. Unzoned phenocrysts have intermediate concentrations $(150-250 \mu \mathrm{g} / \mathrm{g})$ and fine-grained olivine in the matrix has the lowest concentrations $(\sim 100-200 \pm 17 \mu \mathrm{g} / \mathrm{g} \mathrm{Ni})$. The high concentration of $\mathrm{Ni}$ in cores and decrease with crystallization are consistent with a distribution coefficient for $\mathrm{Ni}>1$ and consistent with expected behavior during fractional crystallization [3,4] (Fig 1). Cobalt concentrations in the OPB are lower and less variable than $\mathrm{Ni}$ and, on average, remain roughly constant throughout phenocrysts $(\sim 50-100 \pm 9 \mu \mathrm{g} / \mathrm{g})$ that are zoned in Ni content. However, Co concentrations are slightly lower in matrix olivine $(<40-75 \pm 9$ $\mu \mathrm{g} / \mathrm{g}$ ). Cumulus olivine in the OGC has $\mathrm{Ni}$ and Co patterns that differ from olivine in OPB. The cumulus olivine does not exhibit variations in $\mathrm{Mg}$ and $\mathrm{Fe}$, indicating equilibration. Both the $\mathrm{Ni}$ and Co concentrations have overall flat zoning profiles which could reflect a large reservoir that did not undergo significant change in $\mathrm{Ni} / \mathrm{Co}$ content during cumulus crystallization (Fig 2). Core Ni values are high in OPB $(\sim 400-500 \mu \mathrm{g} / \mathrm{g})$ compared to those in OGC $(\sim 200 \mu \mathrm{g} / \mathrm{g} \mathrm{Ni})$. Results of the Ni and Co measurements combined with modeling support the conclusion that the olivine-phyric basalt is likely to represent derivation from a similar, but more primitive parent melt than the olivine-gabbro cumulate. 
References

[1] B.L. Jolliff et al., Geochimica et Cosmochimica Acta 67 (2003) 4857.

[2] P.K. Carpenter et al., Journal of Research of the National Institute of Standards and Technology, 107 (2002) 703.

[3] J.J. Papike et al., American Mineralogist 84 (1999) 392.

[4] C.D.K. Herd et al., American Mineralogist 94 (2009) 244.

[5] The first author acknowledges the support of a McDonnell Center fellowship. The analytical work was funded by NASA grants NNG04GG10G (RLK) and NNG05GI38G (BLJ).

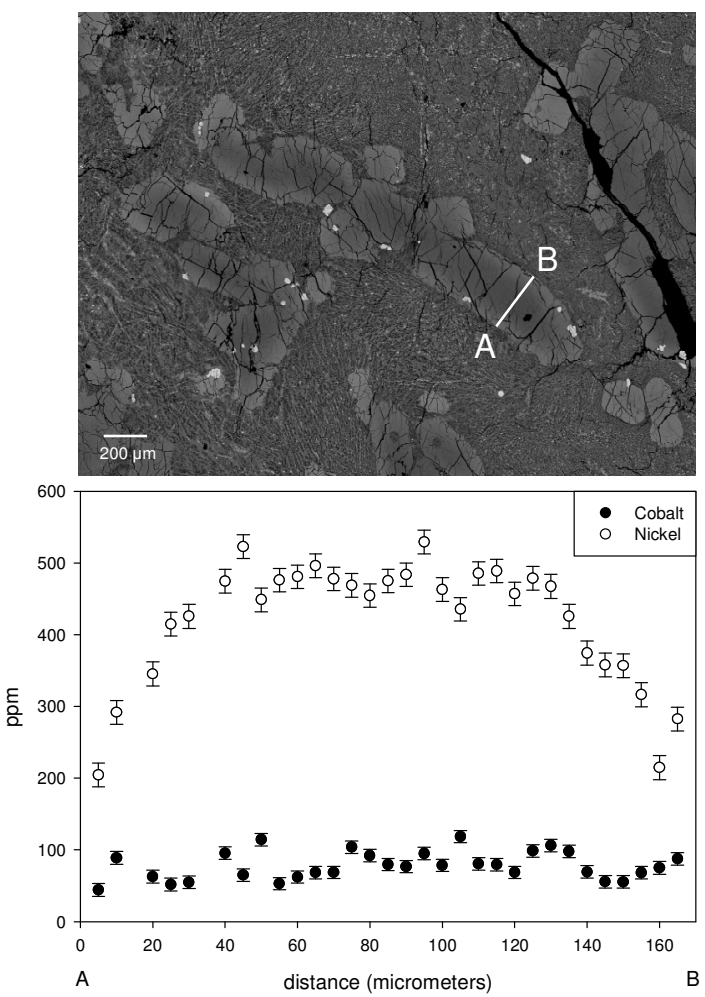

FIG. 1. The point traverse of this zoned olivine phenocryst in OPB extends from rim to rim. The plot shows the rims contains less nickel than the core, which is consistent with crystallization with a compatible trace element. The distribution coefficients for $\mathrm{Ni}$ and $\mathrm{Co}$ were modeled to be 3 and 1.5, respectively.
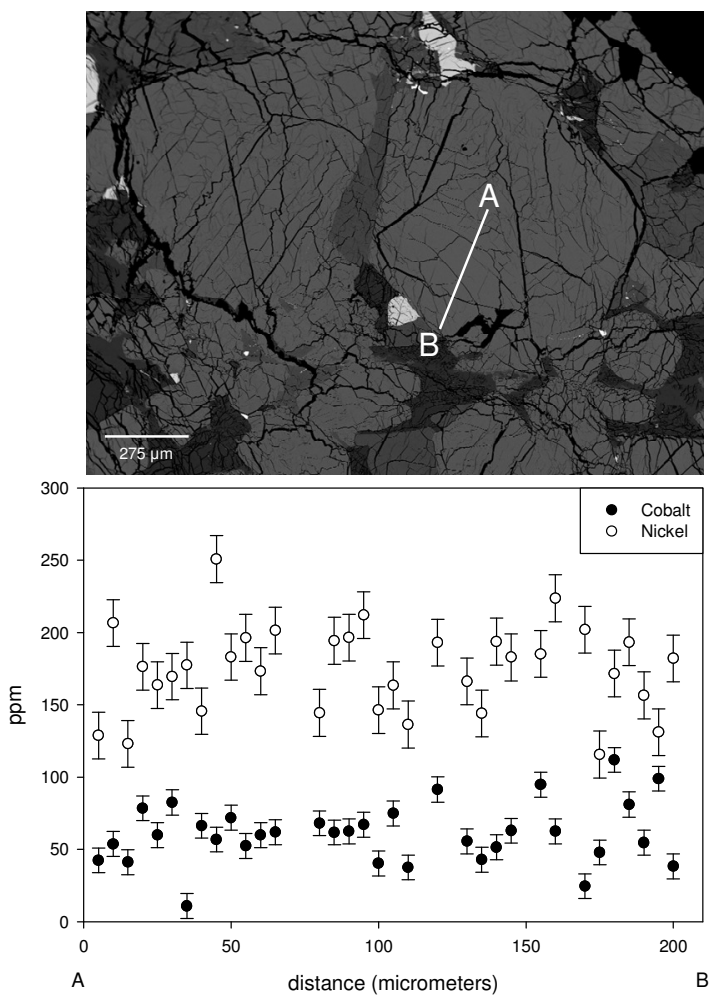

FIG. 2. Point traverse of cumulus olivine in the OGC from core to rim. The olivine composition is $\mathrm{Fo}_{69}$ across the entire traverse. The plot shows the concentration of nickel and cobalt from core (A) to $\operatorname{rim}(\mathrm{B})$.

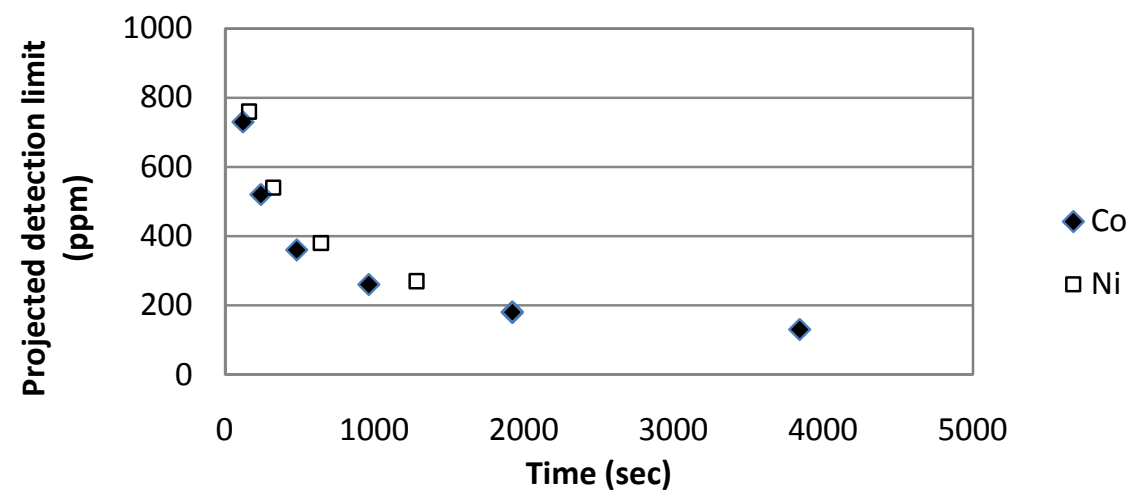

FIG. 3. The graph shows how the projected detection limits change for each element as time increases. 